\title{
MUUX-E, a framework of criteria for evaluating the usability, user experience and educational features of m-learning environ- ments
}

\author{
Patricia Harpur, M.R. (Ruth) de Villiers \\ School of Computing, University of South Africa
}

\begin{abstract}
Higher education students use mobile phones, equipped for Internet access. Mobile technologies can offer effective, satisfying and accessible m-learning experiences. A contribution has been made to knowledge on evaluating m-learning environments and to mobile human-computer interaction (MHCI), with the innovative synthesis of the MUUX-E Framework, which fills a gap in the domain of m-learning. MUUX-E is a single comprehensive, multi-faceted instrument for evaluating m-learning environments, emphasising usability and user experience in mobile educational contexts. It was developed by extensive literature studies on each aspect, and has five categories, 31 criteria and numerous sub-criteria. Using a design-based research paradigm, MUUX-E was applied iteratively to evaluate and enhance successive versions of $m$ - $L R$, a mobile application created for a Software Engineering module. Participants were students and expert evaluators. MUUX-E served well to identify problems and strengths. The students were more positive than the experts regarding the benefits of $m-L R$, yet insightfully reported more system problems.
\end{abstract}

KEYWORDS: Digital difference, evaluation, higher education institutions, M4D, MHCI, m-learning, usability, user experience

\section{CATEGORIES:}

H.5.1 [Information interfaces \& presentation]: Multimedia information systems - evaluation \& methodology H.5.2 [User interfaces]: Evaluation/methodology, theory \& methods-design science research, design-based research

H.5.3 [Group \& organisation interfaces]: Web-based interaction-technology enhanced learning

\section{ARTICLE HISTORY}

Received 6 March 2014

Accepted 10 February 2015

\section{INTRODUCTION}

Mobile handheld devices such as smartphones and tablets are increasingly used for purposes beyond telephony. The traditional classroom is being augmented with m-learning applications for announcements, delivery of learning materials, assessment results, synchronous and asynchronous collaboration, academic social networking, quizzes, online literature sources and digital media [1. Rapidly-changing digital technology has led learners in higher education institutions (HEIs) beyond traditional desktop Internet connectivity to mobile computing. Internet access occurs readily via mobile phone in class, at home, or while travelling. Associated with this is the emergence of a research

Email: Patricia Harpur abc@digilearning.co.za, M.R. (Ruth) de Villiers ruth.devilliers1@gmail.com focus on mobile human-computer interaction (MHCI) 2, 3. Mobile ICT4D, called M4D, is the application of ubiquitous and affordable mobile technology to reduce the digital divide in developing nations 44. In an educational context, m-learning can support all learners and contribute to reducing the gap [5] by providing personal learning opportunities and communication and collaboration facilities [1] both on campus and in remote locations.

To do so effectively and to a high quality, mlearning environments should be evaluated. This article presents MUUX-E, a single comprehensive framework for evaluating $\underline{M}$-learning environments, empha-

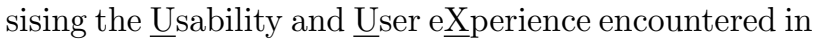
mobile Educational contexts. MUUX-E also addresses general interface usability and educational usability. The primary contribution of this article is in the domain of MHCI, with a focus on evaluation and mobile 
learning, while M4D was part of the study's context.

Section 2 provides background information, while Section 3 is a literature review outlining MHCI, the digital divide and digital difference, m-learning, usability, user experience, and evaluation. The research design and methodology are presented in Section 4. and the synthesis of MUUX-E is explained in Section 5 supported by a detailed literature review. Section 6 discusses findings of an application of MUUX-E in an evaluation study, followed by discussion in Section 7 and the conclusion in Section 8 .

\section{BACKGROUND}

The primary researcher is a lecturer on two South African campuses of a private international university. The two learner bodies are diverse in socio-economic background and in geographical origin. One campus is in the Northern suburbs of the Western Cape, catering mainly to middle-class and more affluent communities. The other is situated in the Southern suburbs and is attended by less affluent students whose backgrounds tend to be digitally-disadvantaged. For several of them, their mobile phone was the only computing device they possessed. In pioneering research, testing the waters, the primary researcher created a prototype mlearning environment called Mobile Learning Research $(m-L R)$, deployed it in a software engineering course, and evaluated it in operation. At the time of this study, students used their own mobile devices to access $m$ $L R$. However, the institution acknowledges the positive impact of m-learning and social networking and, in an ongoing venture, is now delivering digital textbooks on tablet devices. This requires the installation of affordable, effective and safe Internet connectivity on campuses and the provision of mobile hand-held devices to students.

The success of such projects requires positive student attitudes to m-learning, together with satisfactory usability and good user experience in the systems, hence the need for evaluation.

\subsection{Purpose of present research}

Section 2.2 , following, demonstrates the need for effective evaluation mechanisms for mobile learning environments. To address this gap, we:

- synthesised a single comprehensive framework, MUUX-E. The term 'comprehensive' is used because it integrates different perspectives into a single framework, and is therefore a multi-faceted approach for evaluating interactive mobile learning environments; in particular, their usability and user experience in educational contexts.

- applied the criteria of MUUX-E in iterative evaluations of the m-learning environment Mobile Learning Research $(m-L R) . m-L R$ is described in Section 2.3 .

This article relates primarily to the first point, the generation of MUUX-E, but also illustrates the second as we report on applying MUUX-E in an authentic evaluation.

\subsection{The need for an evaluation framework}

There is not a great deal of literature on single comprehensive evaluation frameworks for mobile computing. The need for a framework to investigate m-learning environments is acknowledged by Coursaris and Kim [6] and Deegan and Rothwell [7, who indicate a gap requiring further research.

Coursaris and Kim reviewed mobile usability studies, emphasising the complexity of m-learning contexts incorporating the environment, technology, tasks, users, teaching and learning. Deegan and Rothwell present factors relating to the usability of m-learning applications, suggesting that a framework is fundamental as a foundation for design and development.

Literature sources approach the synthesis of frameworks for m-learning contexts through differing lenses. The following sources provide theoretical frameworks for various facets of mobile learning:

1. Motiwalla [8] investigated feasibility of mobile technology as an extension to e-learning; however UX was excluded, m-learning as a discipline in and of itself was not addressed, and no criteria were suggested;

2. Botha et al. 9 focused on mobile UX, but did not specifically address educational perspectives;

3. Tedre et al. 10] considered educational technology in developing countries, touching on mobile technology, but excluded UX and did not specify evaluation factors. Comprehensive categories and sub-categories were proposed but not evaluation criteria;

4. Vavoula and Sharples [1] proposed a complex gap analysis strategy which is life-cycle oriented and includes evaluation. The data collection strategy was underpinned by recognised design heuristics and focused on technological usability, educational effectiveness and organisational adoption. However no evaluation criteria were provided. UX was mentioned relative to requirements analysis.

5. Ssemugabi and de Villiers 12 synthesised a solid and categorised theoretical foundation of criteria based on a comprehensive literature review and aimed at evaluation of web-based learning (WBL) contexts. The framework comprised three categories of criteria for general interface usability, website-specific considerations and educational aspects, but UX factors were omitted and there was a shortfall of criteria for WBL.

Whilst these frameworks contributed to the synthesis of MUUX-E, they do not meet the designation "framework of criteria for evaluating the usability, user experience and educational features of m-learning environments". Hence the researchers were justified in synthesising a new, more comprehensive, framework.

This article takes evaluation further by stressing the need to evaluate user experience as well as usability. The synthesis of the new evaluation framework is explained in Section 4.2 and Section 5 


\begin{tabular}{|c|c|c|c|}
\hline Software Enginee & ng 2012 & You are lo & ged in as student student (Logout) \\
\hline m-LR Home > SE Home & & & \\
\hline Activities & Tonic outline & & Online Users (mobile) \\
\hline $\begin{array}{l}\text { Chats } \\
\text { CE Forums }\end{array}$ & & & (last 5 minutes) \\
\hline 19 Glossaries & $\begin{array}{l}\text { SE Glossary, } \\
\text { Forum, News, }\end{array}$ & & Random Glossary Entry \\
\hline 纁Wikis & Assessment & & top-down approach \\
\hline Blog Menu & SE Glossary & & $\begin{array}{l}\text { creating a WBS by starting } \\
\text { with the largest items of the }\end{array}$ \\
\hline Add a new entry & SE Forum & & project and breaking them \\
\hline View my entries & SE News & & into their subordinate items \\
\hline Blog preferences & NO SE TNews & & Add your own favorite quotes! \\
\hline & whin SE WIKI & & More quotes... \\
\hline & Follow & & \\
\hline Mobile Access & & D & \\
\hline $\begin{array}{l}\text { There are the following } \\
\text { options to access Moodle } \\
\text { with your mobile phone: } \\
\text { - With a special }\end{array}$ & $\begin{array}{l}\text { TOPIC } 1 \\
\text { Introduction to } \\
\text { the Lessons }\end{array}$ & 口 & \\
\hline $\begin{array}{l}\text { application for mobile } \\
\text { phones (click on }\end{array}$ & This chapter covers: & & \\
\hline $\begin{array}{l}\text { Download): } \\
\text { Download }\end{array}$ & What is a project? & & \\
\hline - Open this adress in the & $\begin{array}{l}\text { What is software } \\
\text { engineering? }\end{array}$ & & \\
\hline
\end{tabular}

Figure 1: m-LR homepage for Software Engineering

\subsection{The m-learning environment $\mathrm{m}$-LR}

$m$ - $L R$, built on a Moodle platform, was a component of an exploratory blended learning approach in a 3rd level Software Engineering module. It provided support for collaborative team-based activities and was enhanced by links to course-related websites. A simple and flexible interface provided access and navigation through course information via PC, tablet or smartphone. Weekly lessons presented course content as hyperlinked chunks, rather than in formal print-style layouts of material and tasks. The platform facilitated formative assessment and included a glossary, wiki, and topic-based forum discussions. Revision exercises with regular click and swipe tests gave instant feedback, in contrast to written assignments. Web 2.0 features (such as blogging and links to a Facebook group) seamlessly extended Software Engineering learning experiences, giving access to learning resources such as lesson summaries, URLs, PowerPoint slides, PDFs and a range of compatible 21st century media (such as YouTube videos). In a constructivist ethos, students contributed to the glossary, wiki and Facebook forum. Secure login screens enabled safe communication between lecturers and learners whilst managing administrative and educational functions.

$m-L R$ evolved through various versions. This evolution is outlined in Section 4.3 of the research design section and the different versions are graphically depicted in Fig. 4. However, Fig. 1 and 2 are extracted from the final version of $m-L R$, and illustrate components of its full functionality. Fig. 1 is $m-L R$ 's home page, offering some of the features in later versions of $m-L R$, such as communication; collaboration; curriculum requirements; multimedia files and learning resources; online resources; and help with mobile access to $m$ - $L R$. Fig. 2 shows part of a revision feature of $m-L R$ in the form of an interactive self-assessment quiz.

Section 6 describes an application of MUUX-E in evaluating the last version of $m-L R$. Findings are presented that can contribute to future m-learning environments.

\section{LITERATURE REVIEW}

The literature review introduces MHCI, outlines the digital divide in higher education in South Africa; defines m-learning, usability and user experience (UX); and considers evaluation in the context of mobile learning.

\section{$3.1 \mathrm{MHCl}$}

HCI is the study of the interaction between users and computing systems with the goal of satisfactorily completing specific tasks [13. In creating interactive environments, essential components are user-centric design, iterative and ongoing evaluation, and awareness of the context in which interaction occurs. Frameworks of principles for the improvement of usability and user experience can scaffold the design of interactive environments 14 .

MHCI focuses on interaction via mobile devices (such as smartphones and tablets), services, and mo- 


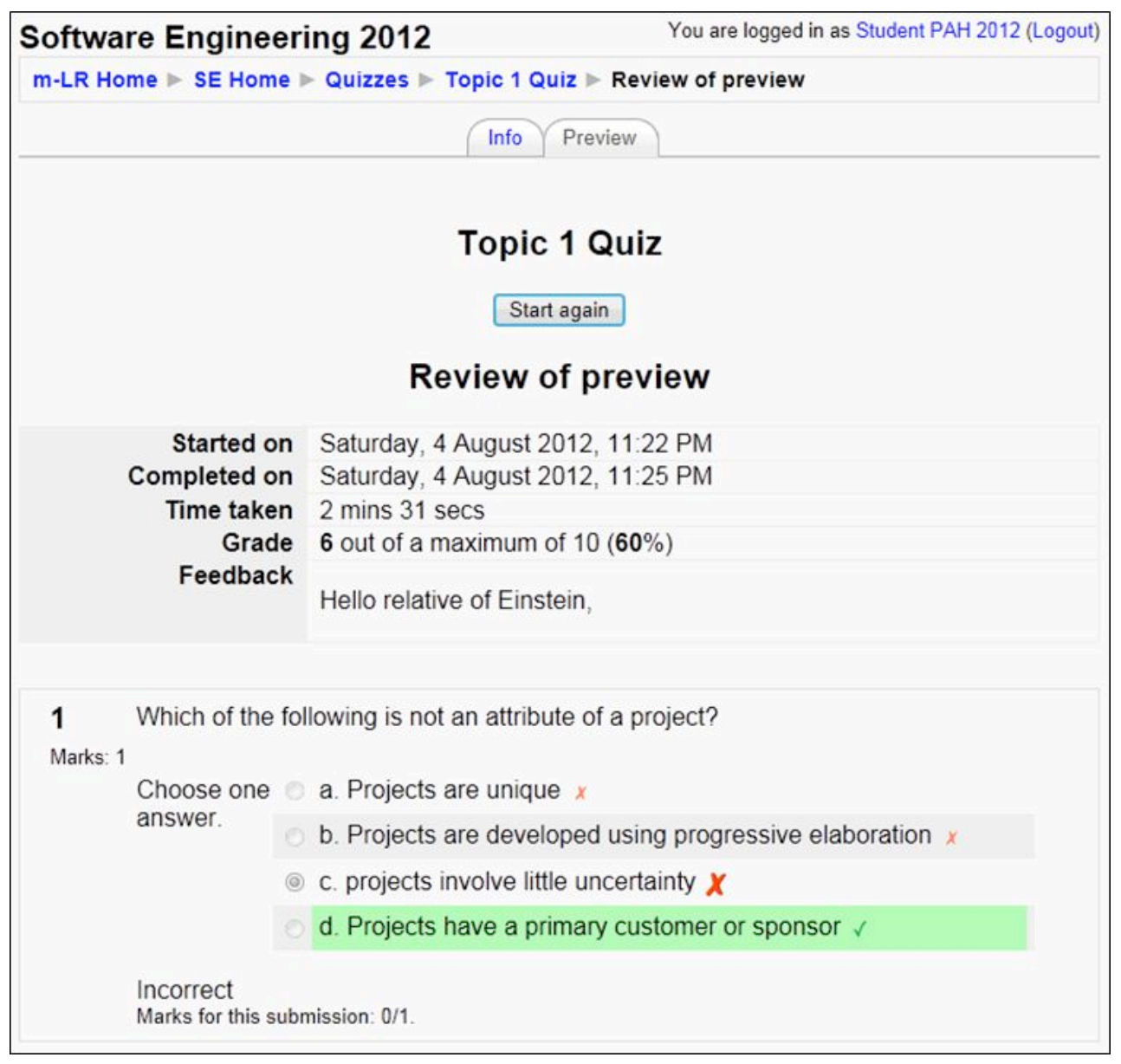

Figure 2: A multiple-choice question associated with the Software Engineering module

bile computing systems [15], and incorporates mobile usability and user experience studies [6].

Research in 2009 by Kjeldskov and Paay on the nature and volume of MHCI publications indicates the emergence of various trends 15 . While studies on projects relating to the engineering of new systems had decreased, the number of publications on user-centric, empirical studies with evaluation foci had increased substantially. Innovative research methodologies were reported, based on the use of multiple methods. Finally, researchers observed shortcomings in MHCI projects, calling for a closer and more holistic relationship between pragmatic design and technology features and hedonic, user experience perspectives. Projects in real-world contexts were encountered, but the need for more such was expressed. In this respect, the present research makes a contribution.

Botha, van Greunen and Herselman [2] propose that interactivity in a mobile context is complex but can be facilitated where barriers have been reduced. Using the term MHCI, they suggest that MHCI can support and enable m-learning. However, in educational contexts, pedagogical requirements should dictate the underpinnings of the m-learning environment, as well as MHCI factors. This observation is reflected in the design of the system of categories, criteria and sub-criteria for educational and m-learning usability guidelines in MUUX-E.

\subsection{Digital divide, digital difference, and M4D}

According to Heeks, M4D should harness the capabilities of technologies in an increasingly digital world, as applications are developed to solve learning problems in technologically-disadvantaged communities by using mobile devices to access the Internet [16].

The 'digital divide' relates to the technology gap and differences in digital literacy between developed and developing communities. This can be relieved by digital 'leapfrogging' via mobile devices [17. The gap termed 'digital difference' occurs in an educational context when HEIs and educators do not deliver on the expectations and requirements of digital students [18.

\section{M4D in higher education}

Mobile devices offer technology to students who lack traditional computing infrastructure. m-Learning initiatives aim for untethered learning in disadvantaged communities, irrespective of time, place, and technological shortcomings. For example, certain HEIs in South Africa have introduced tablets to provide Internet access to digitally-disadvantaged students [19].

In a study prior to this one, the present researchers investigated the profiles and perceptions of two cohorts taking the same software engineering course and identified an intricate digital divide 5. Cohort 1 comprised Internet-wealthy students on a Northern suburbs cam- 
pus, while Cohort 2 in the Southern suburbs comprised mainly Internet-deprived students from South Africa and other African states. The course included collaborative project work via m-learning, which provided uniformity and reduced the digital divide.

In general, Cohort 1 lived close to campus and had their own transport. With their digitally-privileged status, personal laptops, superior campus infrastructure and wireless connectivity, most had reservations about m-learning, since their mobile devices were not equivalent to their alternative computing technologies. Many of the digitally-disadvantaged students in Cohort 2 travelled long distances by public transport. In contrast to Cohort 1, they embraced m-learning, conducted mobile Internet research; and worked on-the-go, also during periods back in home countries. They did collaborative work - and even word processing - via mobile phone. Paradoxically, these students mastered academic use of mobile technology and reduced their own digital divides, compensating for shortcomings on campus and at home [5].

\section{3 m-Learning}

Early attempts by John Traxler to define m-learning recognised it as a distinct concept-spontaneous, situated, informal, and context-aware. He further suggested that m-learning would come to infer attributes, such as connectedness and interactive personalised learning. In general, m-learning may be viewed as e-learning via a handheld digital device, such as a smartphone or tablet, whilst the learner is on the move [20]. A different definition focuses on the device as the mobile facet, combining aspects such as the device; the mobile learning system and the network [21, but disregards the personal mobile context of the learner.

Others stress the human aspects. m-Learning includes three main social factors - control (teachers, learners, technology), context (people, interactive technology, learning situation) and communication (digital formats) 22]. Mobile learning combines mobile usability, wireless technology and an e-learning system, and is available to users who are mobile [21]. Georgiev, Georgieva and Smrikarov [23] point out that $\mathrm{m}$-learning is characterised by a large variety of mobile device types, including netbooks, tablet PCs, personal digital assistants (PDAs), mobile phones and smart phones.

\subsection{Usability}

Conventional usability is defined in ISO 9241-11 as

the extent to which a product can be used by specified users to achieve specified goals with effectiveness, efficiency and satisfaction in a specified context of use. 24

According to Ji, Park, Lee and Yun [25] mobile usability is linked mainly to user satisfaction. They emphasise that, relative to effectiveness and efficiency, user satisfaction is a more relevant measure of mobile usability, since mobile experiences are complex and unique to the user and the context of use. Coursaris and Kim [6] accentuate the complex nature of mobile usability. A mobile context incorporates on-going interactive activities between the user, digital technology and environmental attributes. The usability of a mobile application is impacted by these dimensions.

Certain usability aspects are unique to mobile handheld devices. For example, screen size, keyboard limitations, memory capability and navigability issues, differentiate between the usability of e-learning and usability of m-learning applications. Usability has consequences for learning as it affects adoption, retention, loyalty, trust and satisfaction, all of which are also associated with UX [6], which is the focus of the next subsection.

\subsection{User experience}

User experience (UX) is more subjective and hedonic. In accordance with ISO 9241-210, user experience represents

a person's perceptions and responses that result from the use and/or anticipated use of a product, system or service. 26.

Don Norman of Norman Nielsen Group, an expert in cognitive science and product design, was an early proponent of user experience [27, using the acronym 'UE'. In his book The Invisible Computer, Norman advocates 'human-centred development (HCD)', of which UE is a pillar. HCD commences with users and their needs, not with technology. UE relates to all interactions with a system or product, including its ease of use, how users perceive it and learn it, and how it meets needs with regards to function and aesthetics. Devices should fit the user, not the task.

Norman [27] states that various aspects are required in designing for user experience. Field studies should ensure that a product can be used in its natural setting. Behavioural design should deliver easily understandable conceptual models, supporting the flow of processes. Rapid user testing can determine if a design fits users' real needs, while graphic design provides joy, pleasure and a rich experience by means of aesthetics and intuitive use. Ideally, products should be so intuitive that they can be used without instruction manuals.

Law, Roto, Hassenzahl, Vermeeren and Kort describe UX in the context of all experiences [28, p. 727], suggesting that UX is

dynamic, context-dependent and subjective,

which stems from a broad range of potential

benefits users may derive from a product.

Fig. 3 represents UX as a set of complex and applied learning interactions situated in the context of all learning experiences.

Bevan 29] extends the ISO definition of UX to include users' emotions, beliefs, preferences, perceptions and responses - both physical and psychologicaltogether with what the user has achieved during the experience. He proposes that UX is associated with all the experiences and behaviours that occur before, during and after an activity. 


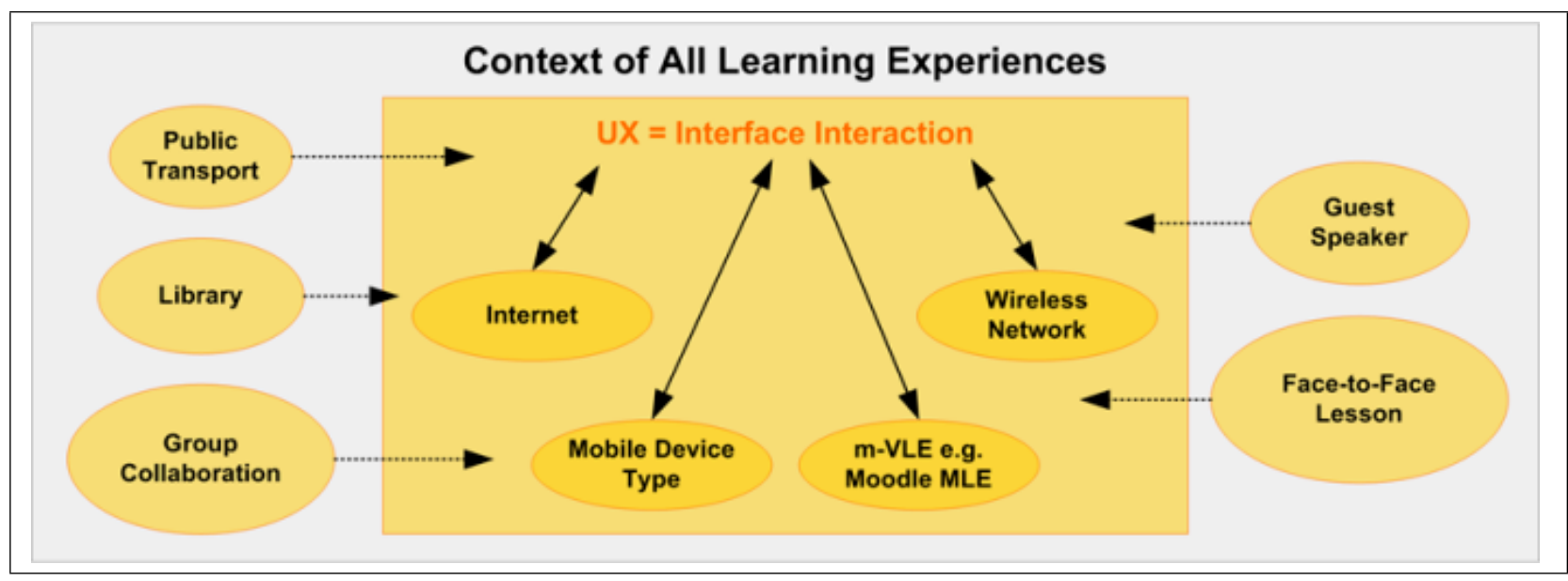

Figure 3: UX as interface interaction in the context of all learning experiences (adapted from [28])

McCarthy and Wright 30 stress senses and emotions, as they discuss UX in the context of 'felt-life', also termed 'lived experience'. The sense one makes of an experience is rooted in feelings such as the excitement, joy or fear it elicits. In the context of HCI and 'technology as an experience' 30, p. 263], felt-life is the relationship between an individual and the tools he/she uses. Life as lived is personal, constructive and transformative, rather than rational. A traditional intellectual and cognition-centred approach to technology focuses on planned interaction, problem solving, learning, and the execution of tasks. By contrast, a felt-life-centric approach involves a new perspective on people-technology relationships as well as on technological activities and practices. It offers an alternative focus to design and evaluation in that felt-life evaluation supports investigation of enchantment and engagement, tenacity despite difficulties, and resistance to a system or artifact. Analysis of felt-life should commence with the user's sensory engagement with technology: the excitement, anxiety, satisfaction, or frustration evoked. Moreover, emotions and value judgements are always directed at an object or person which, in HCI, is the emotion resulting from the use of a technological artifact and how it relates to the user's personal goals 27.

While cognitive information processing examines the efficiency and effectiveness of performance, a process with felt-life at the centre examines feelings, expectations and whether they were met, consistency of feelings, trust, values, and the user's sense of control. The felt-life approach is subjective, unveiling what users value and view as important. It indicates emotional responses to technology and how users act with it. Although it does fit with practice and activity approaches to experiences with technology, it goes beyond cognitive approaches that pay little attention to feelings and subjective awareness. 'Agency' involves one's effect in the world. From the standpoint of lived experience, agency entails stamping actions with one's personal identity and making the action one's own. Human-computer interactions should be designed so that some 'permit the emergence of a sense of agency in interaction' and others deny it [30, p. 268].

Considering the mobile context, Botha, Herselman and van Greunen 31] explore mobile UX (MEX). They suggest that frustration experienced by learners in technology-enhanced contexts, might block rather than facilitate learning. HEIs should seek evidence of the acceptance and likelihood of use of m-learning initiatives prior to their implementation. This highlights the importance of upfront UX evaluation in environments that may be adopted.

\subsection{Evaluation of usability and UX}

Learning environments are more than digital products; they are educational technology artifacts designed to achieve learning objectives. Evaluation strategies for m-learning must differ from conventional usability evaluation, since learning systems have distinct characteristics. Some of the fundamental principles and methods of evaluating e-learning are also relevant to the evaluation of m-learning 32 .

Bevan 29] believes that evaluations of usability and UX are based on different criteria. Similarly, although acknowledging that satisfaction is common to usability and UX, Petrie and Bevan [33] introduce criteria that treat usability and UX as separate concepts, but evaluated in parallel. Roto, Obrist and Väänänen-Vainio-Mattila [34] express interest in mixedmethod evaluations where both pragmatic (usability) aspects and hedonic (UX) factors are combined. Criteria should be customised to fit the m-learning system being evaluated 35 .

Proponents of felt-life centricity 30 posit that HCI activities can be evaluated by integrating the facets of interactivity and interpassivity to analyse engagement. One-sided interpassivity occurs when tasks are done without a sense of relating. One-sided interactivity occurs when a task is done, but by indirect means. The ideal is mutual interactivity, when a technologically-mediated experience engenders creative use of technology, enhancing UX.

With this background, we address the gap identified in Section 2.2 by presenting MUUX-E, a single, multi-faceted evaluation framework, including criteria 
for evaluating interfaces and educational features, but that emphasises the evaluation of usability and UX in the context of m-learning. The methodology used to synthesise MUUX-E, is outlined in Section 4.2, while the actual synthesis is presented in Section 5.

\section{RESEARCH DESIGN \& METHODOLOGY}

\subsection{Research questions}

This manuscript aims to answer the following questions:

1. What categories and criteria should be included in a usability and UX evaluation framework for m-learning environments?

2. What are the outcomes of applying the MUUX-E Framework to evaluate $m-L R$ for usability, UX and educational features?

These questions are answered in Sections 5 and 6 , respectively.

\subsection{Research design: Synthesis of the MUUX-E evaluation framework}

Frameworks can serve varying purposes in research. Conceptual frameworks represents set of objects, functions, processes, and the inter-relationships between them, frequently doing so graphically [36, 37].

Evaluation frameworks [11, 12, 38, 39] are simpler structures, usually presenting categories of evaluation criteria in a tabular format. The present work introduces a single integrated evaluation framework, MUUX-E, developed for the purpose of evaluating interactive mobile learning environments. The methodology used to generate MUUX-E, was a set of studies of existing evaluation models, followed by separate studies of interface heuristics, web-based learning, usability and UX factors in mobile learning. MUUX-E was thus synthesised by an extensive literature review, using literature as secondary data and classifying it into categories and criteria. The evaluation and design concepts encountered, provided a theoretical grounding for MUUX-E.

1. Initially searches were conducted to identify existing multi-category frameworks. As indicated in Section 2.2, of the five investigated, no single framework was deemed ideal for the requirements of this study.

2. Then we studied literature on smaller-scale facets of m-learning to determine single features and requirements.

Both types of material were used to generate focused criteria which we incorporated into the new framework. The criteria in the final framework (Appendix A) were converted to questionnaire items for an empirical evaluation with $m$ - $L R$ as target system (Appendix B is an extract from the evaluation instrument). MUUX-E is intended for comprehensive evaluation of m-learning systems and environments, yet with a strong focus on usability and UX. MUUX-E, and its development, is presented in Section 5 .

\subsection{Research design: development of $m-L R$}

The underlying research design of the $m-L R$ environment, whose evaluation is used in this study to demonstrate an application of MUUX-E, is design-based research (DBR) 40, the educational-technology variant of design research. DBR involves iterative development and evaluation of an artifact. 'Design science' originated from Herbert Simon [41 and led, in turn, to design research, which in Information Systems (IS) is called 'design-science research' (DSR) 42, 43, 44, and in educational technology is often termed 'design-based research' (DBR) [45, 46, 47] or 'educational design research' 48.

Fig. 4 shows the iterative development of $m-L R$, as it evolved through successive versions in response to findings of evaluations using the MUUX-E Framework. The outcomes of each iteration led to improvements to $m$ - $L R$. The Main Evaluation (Evaluation Study 4 in Fig. 4, is the application of MUUX-E discussed in Section 6. Fig. 4 also shows the classic dual outcomes of DBR: of which the m-learning environment, $m-L R$ is the practical outcome and MUUX-E is the theoretical contribution. Despite its position alongside the practical outcome to show it as a culminating contribution of the research, MUUX-E emerged early, evolved marginally in the process, and its criteria were applied throughout.

\subsection{Research methods used in applying MUUX-E}

An application of MUUX-E is described in Section 6, namely the use of MUUX-E in Evaluation Study 4 in Fig. 4 below.

In conducting an evaluation, a researcher requires evaluation methods and evaluation criteria. The criteria can be combined with various data collection methods. The methods selected for use in this study were

- heuristic evaluation (HE) 13 by five expert evaluators, who were experienced educators, and

- a user-based method, namely questionnaire surveys 13 among 32 learners - 19 from the Northern suburbs campus and 13 from the one in the Southern suburbs.

The criteria that comprise MUUX-E are presented in Table 1 in Section 5, which explains the construction of MUUX-E.

\subsection{Research ethics}

Ethical clearance was obtained from the university where the research was conducted and from UNISA, where the primary researcher was registered for postgraduate studies. Participants signed informed consent forms, which also acknowledged that findings might be published in academic publications. 


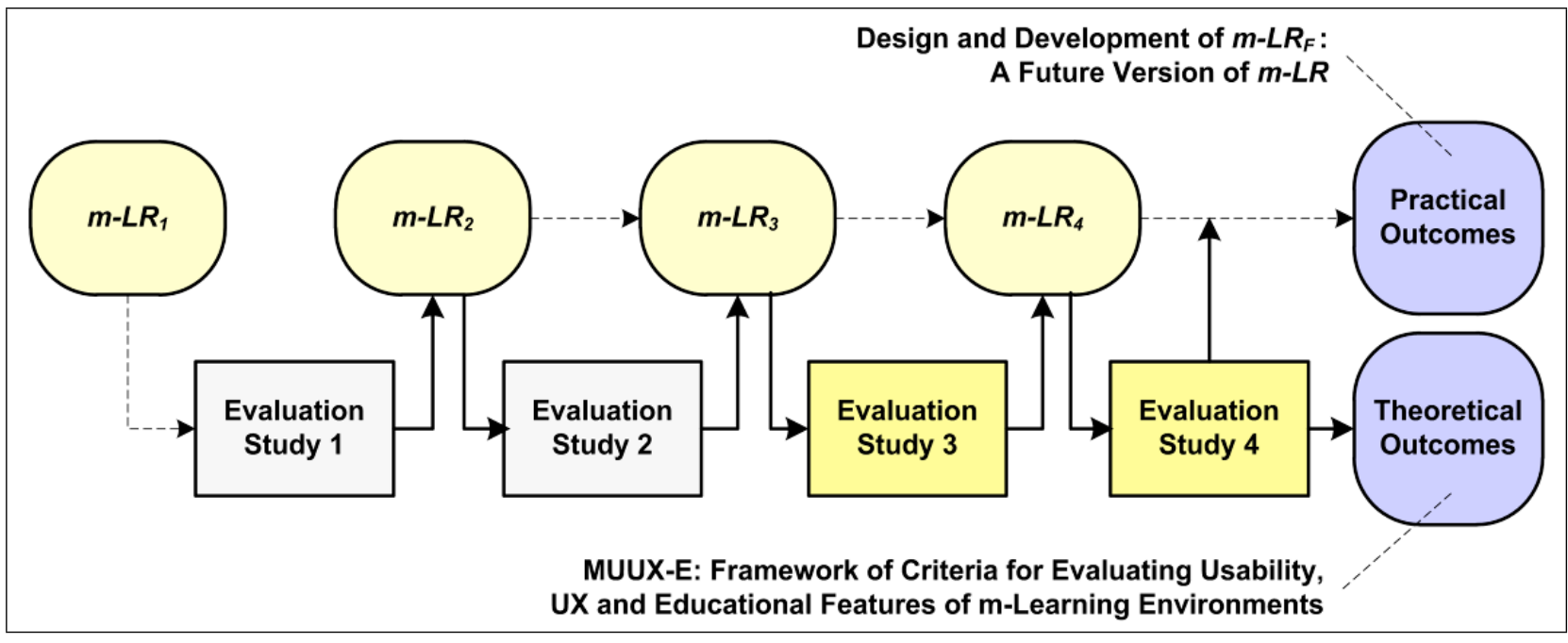

Figure 4: Iterative evaluations of versions of m-LR (adapted from [40])

\section{SYNTHESIS OF MUUX-E}

The construction of the MUUX-E Framework, comprising categories of evaluation criteria, was undertaken to synthesise a single comprehensive evaluation framework for multi-faceted investigation of interactive web-based mobile learning systems. It streamlines data gathering and analysis, enabling uniform types of data to be collected efficiently and effectively from all participants. As stated, the DBR paradigm aims for practical and theoretical outcomes. MUUX-E, as a contribution to knowledge on evaluating m-learning environments, was the theoretical outcome (see Fig. 4).

\subsection{Structure of MUUX-E}

The evaluation of m-learning environments should incorporate factors distinct to the domain of mobile technologies [11. From the review of existing literature, five distinct categories emerged: general interface usability, web-based learning, educational usability, m-learning features, and user experience.

Fig. 5 illustrates the structured approach used to synthesise MUUX-E. The categories are briefly overviewed before addressing them in Section 5.1. Evaluation should emphasise both usability and UX [49]. State-of-the-art evaluation guidelines for interactive technologies include hedonic, affective and aesthetic user experience dimensions, involving emotions and subjective impressions of users' experiences. There should be pragmatic usability criteria [14, entailing general interface usability and educational usability, attributes of which focuses on effective learning. Practical web-specific aspects and m-learning factors must also be addressed. Section 5.1 prepares the scene for Table 1, an abbreviated MUUX-E Framework, by articulating how it was grounded in literature on existing evaluation models and on topic-specific aspects. The criteria and sub-criteria within the categories were defined to establish a broad and deep understanding.

\subsection{Evaluation categories}

The development of the MUUX-E Framework commenced with studies of existing models and frameworks listed in Section 2.2. These provided points of departure. Aspects of Ssemugabi and de Villiers' Framework for Evaluation of Web-based Learning Applications 12 were customised and extended/reduced to establish the first three categories of evaluation criteria, namely 'General Interface Usability'; 'Web-based Learning'; and 'Educational Usability'. Vavoula and Sharples 11 advocate that specific m-learning criteria be combined with general usability guidelines and learning factors into a customised list of criteria for mobile devices. In addition, the emerging framework was influenced by Motiwalla [8] and thus augmented by Category 4, 'm-Learning Features'. The affective criteria in Category 5 on 'User Experience' originate in classic UX sources, as well as recent work by Botha et al. 9] 31, m-learning literature, and other sources on mobile UX or UX in general.

\section{General interface usability}

This category reflects Nielsen's classic heuristics for interface usability 50. System design should be characterised by consistency and aesthetics, and should meet learners' needs in a familiar real-world way. Error prevention, detection and recovery are important, as is cognitive facilitation.

\section{Web-based learning (WBL)}

An m-learning system is also a WBL application, therefore the following should be investigated: simplicity of site navigation, organisation and structure; relevance and format of site content to the learner, and its suitability for the learning process [12, 27, 51. Course material should be easily accessible, and tailored for a web context. Digitised material such as video and podcasts should be of a high quality and deliverable to all device types via an easy-to-use system [6, 52, 53]. 


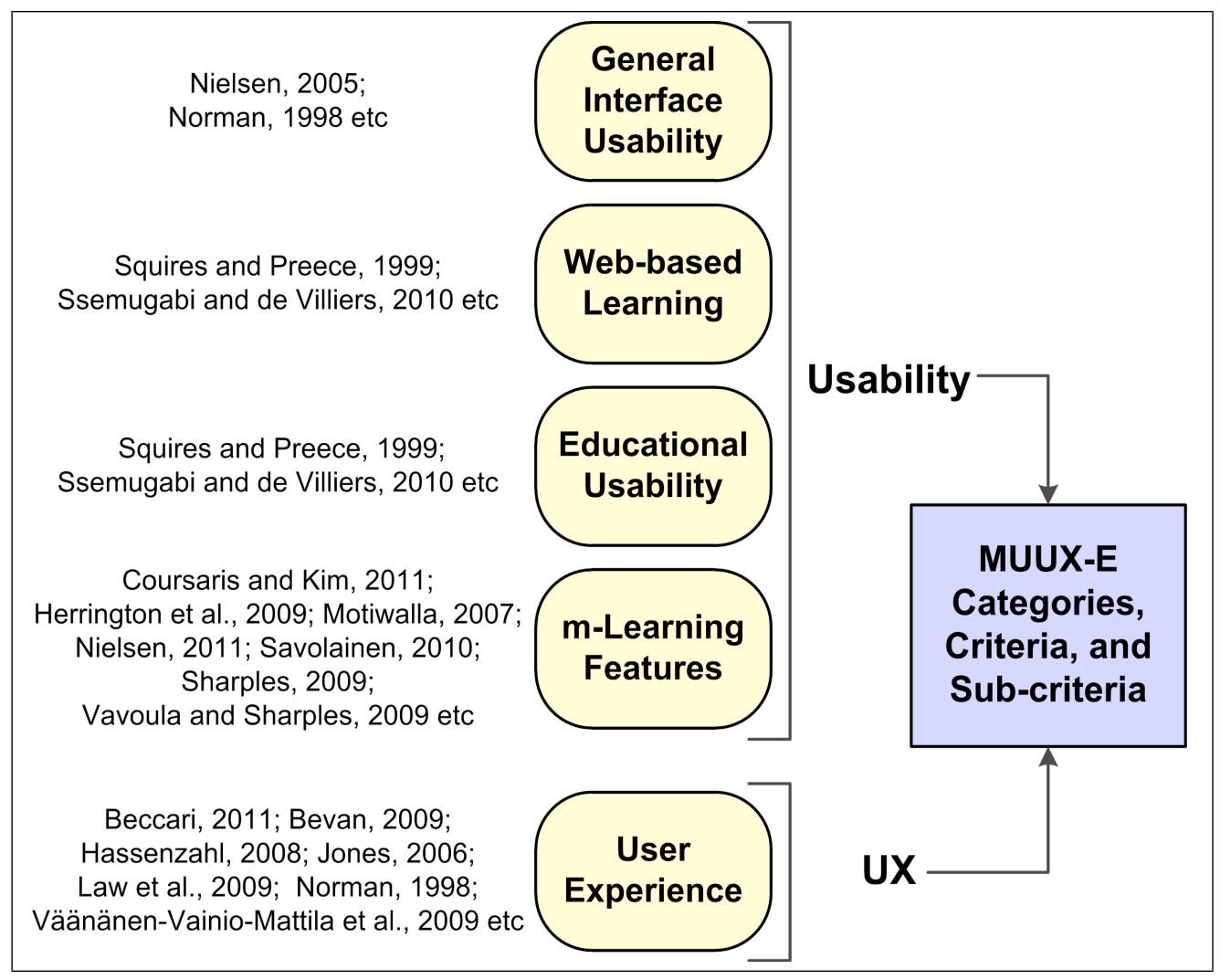

Figure 5: Conceptual outline for MUUX-E

These features should positively support the learning objectives.

\section{Educational usability}

Educational usability differs from conventional usability in that it stresses learning-specific use and the relationship of the content to objectives, learning processes and outcomes. Irrespective of the mode of delivery, education and the transmission of knowledge should be grounded in sound learning theory 51 . Attention should be paid to pedagogical factors such as motivational goals, contextual objectives, and required outcomes of active learning. Cognisance should be taken of learner-specific needs, e.g. their ability to be creative and to control their learning processes. Timeous feedback, guidance and assessment should support meaningful assimilation of course content [12].

\section{$\mathrm{m}$-Learning features}

It was essential to include factors specific to m-learning environments. Although Sharples 54 suggests that Nielsen's ten heuristics are adequate for evaluating mobile device usability, Nielsen himself asserted in 2011 that up to 210 criteria could be required 55 . Specific m-learning criteria should be integrated with usability guidelines and learning aspects to generate a customised list of criteria [11. m-Learning is a complex and contextual learning modality [11, 56, 57] requiring consideration of many aspects of the mobile-learning context such as: numerous types of handheld devices 6. 58, 55]; the affordances and limitations of underlying mobile technologies [53, 8; user-centricity [56, 52 and flexibility in the application of m-learning principles [59. In addition, collaborative activities are impacted by multiple forms of user mobility and interactivity 53, 59.

\section{User experience}

$\mathrm{m}$-Learning can be motivational and even fun 60, as it enables greater participation with more time to personally process content 61 . Bevan 29 suggests that high user satisfaction implies the attainment of both pragmatic and hedonic goals, which is broader than the satisfaction associated with usability 24. Satisfaction can thus be viewed as part of UX, incorporating pleasure, motivation and achievement. Moreover, UX includes anticipation of an experience, the experience itself and post-experience perceptions [29].

To a large extent, the success of m-learning depends on the hedonic aspects of learning and users' personal perceptions, and the ability to evoke both sensual and emotive experiences 30. MUUX-E incorporates hedonic factors in its UX categories, such as the criteria under 'Emotional issues' and 'Satisfaction'. The relevance to learning of user experiences is considered where design elements provide for involvement and personalised learning [27, 62].

Emotional factors encompass affect, excitement, interest, attitude, fun, joy, well-being, and beliefs 60 61. The influence of context is personal, complex and highly relevant for m-learning where user attitudes may affect the manner in which the learning episode is experienced [27, 28]. 
Table 1: MUUX-E categories of criteria for evaluating features of m-learning environments

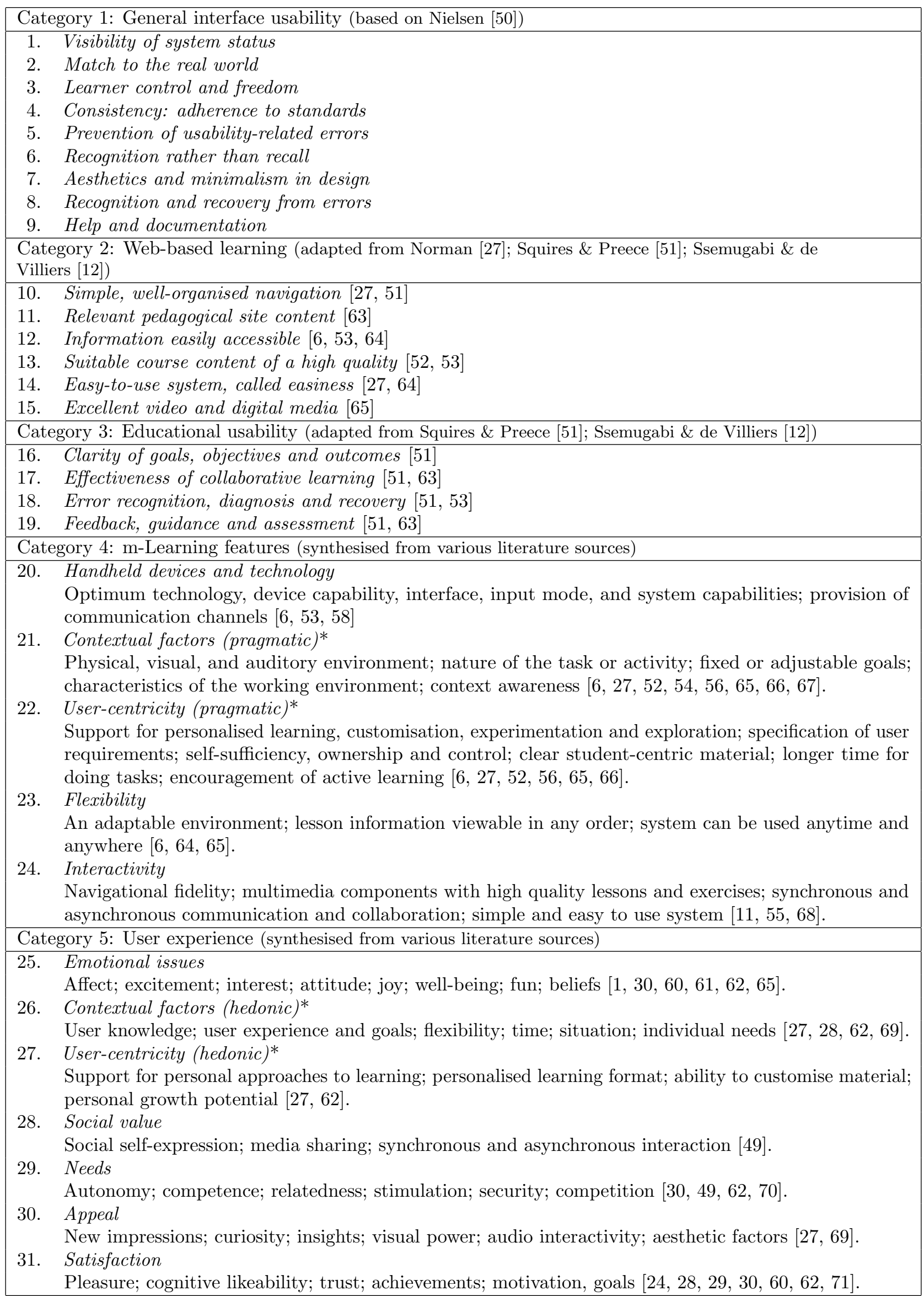

* Note: contextual factors and user centricity are addressed in both Category 4 and Category 5 . Category 4 addresses the pragmatic aspects of the criteria, while Category 5 considers hedonic perspectives. 
m-Learning should capitalise on the social aspects of mobile technology, embedding social value into learning experiences so that users can express themselves whilst sharing media and interacting synchronously and asynchronously [49. Needs of m-learners extend to stimulation, security, competition, autonomy, competence and relatedness [49, 62, 70]. An m-learning system should be appealing. Users need to have engaging and satisfying experiences, whilst gaining new insights and communicating in powerful yet aesthetic ways by visual and auditory means 69 . User experience reflects levels of satisfaction with the m-learning environment, the attainment of personal goals and sense of achievement [28, 29, 60, 62].

\section{Final MUUX-E Framework}

The five categories of the preceding subsections are consolidated and listed in full in Table 1.

Table 1 presents a concise version of the final MUUX-E Framework, comprising five categories and 31 criteria, along with references. Each criterion was further defined as a set of detailed sub-criteria in the full version of MUUX-E, which is in Appendix A. In the associated research instruments, namely the $\mathrm{HE}$ and the student survey, the sub-criteria were converted to evaluation items. A section of the HE questionnaire is shown in Appendix B. MUUX-E was validated in use, as its utility was tested by application in the series of evaluation studies in Fig. 4. It was refined and marginally extended during the DBR process.

\section{APPLICATION OF MUUX-E}

The primary intention of this article is to introduce the synthesised MUUX-E Framework for evaluating m-learning environments and systems. A secondary aim is to illustrate its application by briefly describing the main evaluation, Evaluation Study 4 in Fig. 4, and selected findings. The input to the study was version $m-L R_{4}$ and the findings are intended to improve and refine it, leading to a future version.

Two research methods were used to collect data: heuristic evaluation by five expert evaluators, E1, E2, E3, E4 and E5, and a questionnaire survey among 32 learners, comprising the populations of both cohorts19 from the Northern campus and 13 from the Southern. The experts held various academic roles. Three of them had more than 10 years' experience.

E1 Lecturer and course developer in IS and HCI double expert: subject matter and usability (MSc);

E2 Senior lecturer, Artificial Intelligence $(\mathrm{PhD}$ in progress);

E3 Lecturer, Software Engineering and Knowledge Management, IS project leader (MTech (IS));

E4 Lecturer, Database design project manager (BSc Hons);

E5 Instructor, Computer science and ICT.

Based on MUUX-E, questionnaires were generated by mapping criteria to evaluation statements. An extract from the instrument used in the $\mathrm{HE}$ is included as Appendix B.

\section{Empirical findings: evaluation indices-Table 2}

It is not possible to report the extensive results of the evaluation, but Table 2 summarises the empirical findings from experts and students as evaluation indices, showing the means of five-point Likert scale ratings, where a rating of ' 5 ' indicated the highest rating and ' 1 ' the lowest.

Table 2: Evaluation indices from Study 4

\begin{tabular}{|ll|c|c|}
\hline \multirow{2}{*}{ Categories of evaluation criteria } & \multicolumn{2}{|c|}{ Evaluation indices } \\
\cline { 3 - 4 } & Experts & Students \\
\hline 1 & General interface usability & 3.6 & 3.9 \\
3 & Web-based learning & 3.5 & 4.0 \\
4 & Educational usability & 3.6 & 4.0 \\
4 & m-learning Features & 3.9 & 3.9 \\
5 & User experience & 3.7 & 4.0 \\
\hline \multicolumn{2}{|c|}{ Overall } & $3.7 *$ & $4.0 *$ \\
\hline
\end{tabular}

for Experts and Students are statistically significant

The student participants rated interface usability as satisfactory with an overall rating of 3.9 for Category 1. The means of 4.0 for Categories 2 and 3 indicate good usability and reflect the resilience and independence of students in an m-learning environment. Findings in Categories 4 (3.9) and 5 (4.0) also demonstrate positive perceptions.

Students assigned higher ratings than the experts, indicating a more positive attitude to the potential of m-learning to scaffold educational goals. They found the m-learning environment more familiar and more fun than the experts did.

The overall mean Likert rating of 3.7 by experts shows a less positive perception than the 4.0 mean of the students.

\section{Empirical findings: problems-Fig. 6 and Table 3}

Fig. 6 provides a comparative view of the numbers of problems in $m-L R_{4}, 28$ identified by experts and 62 by students, illustrated per category and in total.

Using the categories and criteria in MUUX-E, participants effectively identified problems in $m-L R_{4}$. Analysis of this open-ended qualitative input generated eight themes: design and development; ease of use; mobile specifications; content; context; learner-centricity; VLEs; and Web 2.0 tools.

These themes provided valuable insights and generated design guidelines necessary for subsequent versions of $m-L R$.

Table 3 presents problems that emerged from the qualitative student input. The responses relate to Category 1: General Interface Usability. Due to space limitations, the experts' input is not shown. The first column lists some responses from participants to questions associated with Criterion 1, 'Visibility of system status' in the survey instrument. 


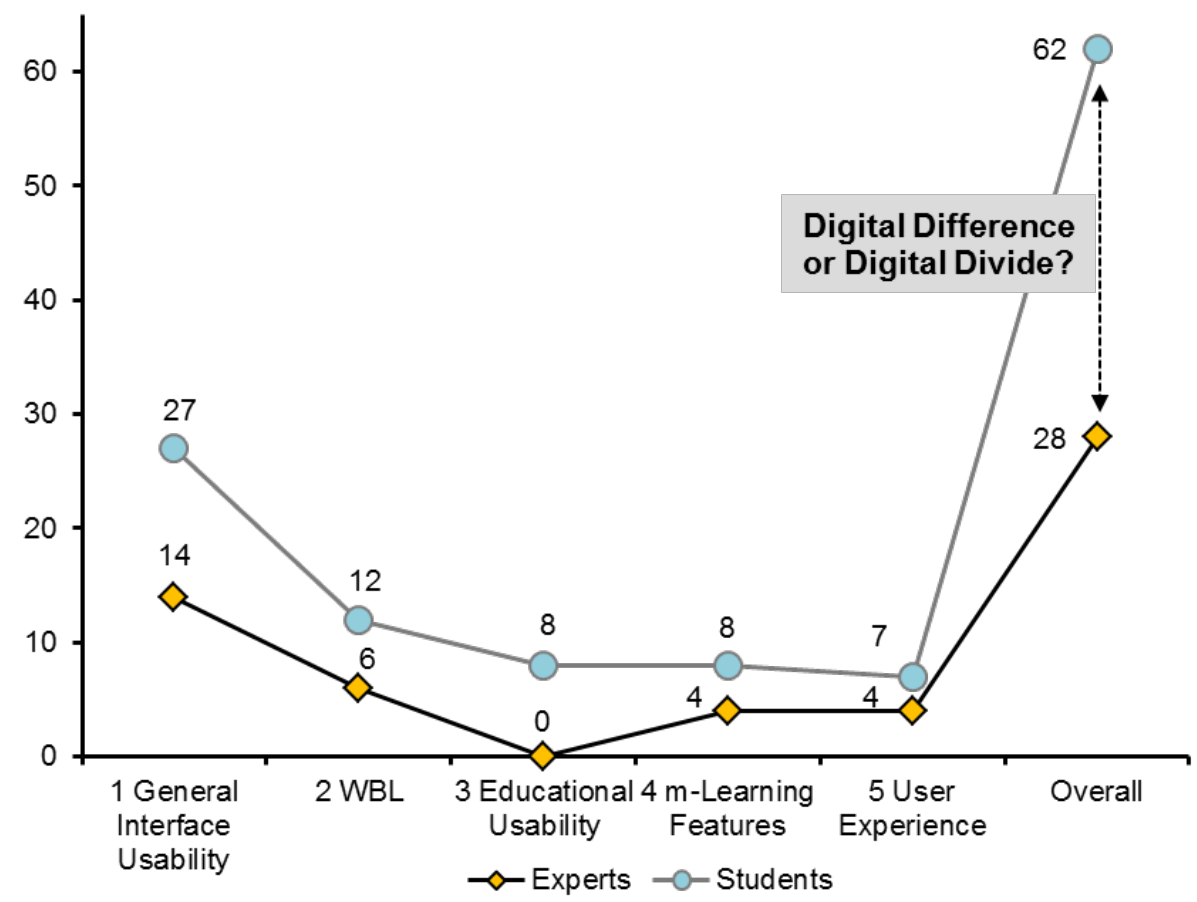

Figure 6: Number of distinct problems reported by experts and students

Table 3: An excerpt from the thematic analysis of problems reported by students

\begin{tabular}{|c|c|c|}
\hline $\begin{array}{l}\text { Category 1: General interface usability } \\
\text { 1. Visibility of system status, provide feedback }\end{array}$ & Theme & Design guidelines \\
\hline $\begin{array}{ll}1 & \text { Mobile phone network issues, long loading time } \\
2 & \text { Cellphone was just a bit small } \\
3 & \text { Some content did not load correctly, perhaps it was my } \\
& \text { connection } \\
4 & \text { It isn't available for my phone }\end{array}$ & $\begin{array}{c}\text { Device } \\
\text { constraints }\end{array}$ & $\begin{array}{l}\text { Mobile } \\
\text { specifications }\end{array}$ \\
\hline $\begin{array}{ll}5 & \text { There is no quiz for this topic } \\
6 & \text { I couldn't see the quiz }\end{array}$ & Assessment & VLEs \\
\hline $\begin{array}{cl}7 & \text { To me the navigation is confusing at most times } \\
8 & \text { Could not find or read some of the apps } \\
9 & \text { I find navigation to be confusing at times } \\
10 & \text { Seems like you are going in circles sometimes }\end{array}$ & Navigation & Ease of use \\
\hline Identified that the modules were from last year & Design & Design and development \\
\hline 12 A bit busy at times & Look and feel & Design and development \\
\hline $\begin{array}{l}13 \text { I don't understand some of the feedback } \\
14 \text { Sometimes I don't know if I can answer the question as } \\
\text { I'm not sure if the application did what it was meant to } \\
\text { do, otherwise, works very well }\end{array}$ & Feedback & Ease of use \\
\hline
\end{tabular}


The responses in column one of Table 3 relate to distinct problems encountered, while the second and third columns classify the themes and guidelines that emerged. Table 3 shows that Criterion 1 led to six themes and four distinct design guidelines.

The use of two data collection methods in tandem, heuristic evaluation and student surveys - both of which were based on the MUUX-E criteria, proved synergistic in detecting weaknesses in $m$ - $L R_{4}$, some pertinent to experts and others unique to students. This phenomenon may reflect a digital difference between expert and student evaluators, since many of the students were more skilled in current technologies than the expert evaluators, who were mainly educators. In total, the 32 students detected 62 dissimilar problems in $m$ - $L R_{4}$, amounting to $121.4 \%$ more than those uncovered by five experts. The greatest number of issues (27) came from Category 1, General Interface Usability, comprising $43.5 \%$ of all problems reported by students.

This phenomenon of students identifying more distinct issues than experts, contrasts with another study 12 in which four expert evaluators identified 58 problems and 61 students identified fewer, namely 55 , which is $95 \%$ of those uncovered by the experts. It is a natural expectation that experienced experts would find the most problems. It is therefore notable when a student group identifies more than the experts did, as occurred in the present research. A likely reason is that the application was not a PC-based website as in the other study [12, but an m-learning environment running on a mobile device - a domain in which youth are frequently more competent and confident.

\section{DISCUSSION AND REFLECTION}

This research on the theory and practice of evaluation contributes to the MHCI domain and satisfies several of the tenets highlighted in Section 3.1:

\section{Framework of principles to improve usability and UX}

A structured approach to evaluation can benefit MHCI research projects. A single collection of categories of criteria, such as the MUUX-E Framework, can be customised to suit the environment and sub-criteria can be selected for local situations.

A close, holistic relationship between pragmatic design and technology features and hedonic perspectives

The research undertaken while synthesising MUUX-E (Section 5) had two important new foci. Pragmatic mobile features and technological aspects were incorporated (Category 4) and, secondly, the user experience offered by m-leaning environments was addressed (Category 5$)$.

\section{Projects in real-world user-centric contexts}

After its generation, MUUX-E was applied in evaluating the authentic environment, $m-L R$ (Section 6).
With regard to user-centricity, Criteria 22 and 27 investigate the important aspects such as personalised learning, ownership and control, and student-centric learning material.

\section{Cognisance of pedagogical requirements}

Two of MUUX-E's categories (Categories 2 and 3) relate to learning and educational factors.

The study also raises other notable points.

\section{Expert-student evaluators}

Findings of this evaluation study suggest, paradoxically, that in the domain of mobile technology, student users may be more 'expert' than experts. The overall evaluation indices of experts (3.7) and students (4.0) were statistically different, with students having the more positive attitude to m-learning. Although they were positive in their feedback, students insightfully reported many more distinct problems in the target system (62) than the experts did (28). It is posited that this is an incidence of the digital difference introduced in Section 3.1. Educators should acquire digital expertise and skills to cope with the current era.

MHCI research projects which investigate mobile technology-enhanced learning initiatives, should acknowledge the new generation of interactive technosavvy participants. These young 'experts' have the potential to simultaneously take the roles of producer and innovator 4, as well as evaluator. This observation impacts on the design of MHCI applications, as well as on the research design and methodology underpinning MHCI projects.

\section{Digital divide and digital difference}

m-Learning can transform the learning experiences of digitally-disadvantaged students. Evaluation findings have implications for M4D that go beyond evaluation of target systems. Evaluation of an m-learning environment that operates in multiple locations may indicate inter-campus digital divides and intra-campus technological inequities. Evaluations can also unveil digital differences between the participants, in this case the experts and students. Pedagogical experts should be challenged on these differences and on their attitudes to technology-enhanced learning. Where necessary, educators should undergo skills training.

\section{Filling the identified gap}

This submission has addressed the gap identified in Section 2.2 by presenting a single, multi-faceted evaluation framework, MUUX-E, synthesised for mobile learning (Section 3.6; Section 4.2 Section 5). MUUX-E includes five categories of criteria. There are criteria for evaluating interfaces, usability and learning aspects and distinguishing this research and the emerging comprehensive framework criteria for evaluating m-learning features and user experience, all explicitly contextualised for m-learning environments. 


\section{CONCLUSION}

We re-visit the research questions and implications for MHCI, followed by recommendations.

\subsection{Revisiting the research questions}

The research questions (Section 4.1) were:

1. What categories and criteria should be included in a usability and UX evaluation framework for m-learning environments?

2. What are the outcomes of applying the MUUX-E Framework to evaluate $m-L R$ for usability, UX and educational features?

In keeping with a DBR paradigm (Fig. 4), there are dual outcomes: a theoretical contribution in the form of the MUUX-E Framework of categories and criteria; and a practical outcome, the evaluation of the mobile learning environment, $m-L R$, and also $m-L R$ in and of itself. These are reviewed in Sections 8.2 and 8.3 respectively.

\subsection{Theoretical contribution: an evaluation framework for m-learning environments}

The MUUX-E Framework of categories and criteria is presented in Section 5, Table 1 and in Appendix A. The primary purpose of this research was to produce a framework for structured evaluation of m-learning environments, thereby answering Question 1. The criteria were generated from the literature, grounding this work as a theoretical contribution to the bodies of knowledge on m-learning and evaluation and hence to MHCI. MUUX-E was validated and refined by use in the evaluation studies in Fig. 4. Evaluation with MUUX-E makes a particular contribution to the body of knowledge on evaluation due to its emphasis on hedonic, affective and aesthetic user experience dimensions, as well as pragmatic usability criteria. Use of this single comprehensive framework with its 31 criteria and numerous sub-criteria, provides thick and rich evaluation findings that can be used to improve m-learning environments.

\subsection{Practical contribution}

Question 2 involved the practical application of MUUX$\mathrm{E}$ in evaluating a particular operational m-learning environment, $m-L R$. The extensive and detailed findings of the evaluations are beyond the scope of this article, and can be reported in another publication. Nevertheless, the abbreviated findings in Section 6 illustrate the value of the MUUX-E criteria, applied iteratively to evaluate sequential versions of $m-L R$ via expert heuristic evaluation and a questionnaire survey among students. In particular, the comprehensive Evaluation Study 4 by the entire student populations of both campuses, unveiled problems in $m$ - $L R$ that had not emerged when earlier versions were evaluated in smaller-scale studies conducted on one campus only (Evaluation Studies 1, 2 and 3; see Fig. 4).
MUUX-E criteria and sub-criteria are generic. They can be transferred, adapted, customised, reduced or augmented for other MHCI evaluation studies; for evaluation of other m-learning environments; and for evaluation by the same, or other, evaluation methods.

\subsection{Recommendations}

The study promotes quality standards for m-learning environments and aims to improve usability and user experience. In this regard, MUUX-E provides a sound and customisable template, underpinned by theoretical principles that can be used in evaluating mobile technology-enhanced learning applications in tertiary education contexts.

The strategies of educators, developers, policymakers and administrators, should explicitly incorporate effective and efficient m-learning environments. It is important, however, that such environments should also satisfy the hedonic needs of students.

Just as MUUX-E was built to evaluate m-learning environments, we advocate the creation of similar multi-faceted evaluation frameworks for mobile systems in other domains, for example, mobile health applications (MUUX-H), m-government (a series of MUUX-G frameworks), mobile retailing (MUUX-R), and so on.

\section{REFERENCES}

[1] K. MacCallum and K. Kinshuk. "Mobile technology in collaboration: Evaluation of a web-based discussion board". International journal of mobile learning and organisation, vol. 2, no. 4, pp. 318328, 2008. DOI http://dx.doi.org/10.1504/IJMLO. 2008.020685 .

[2] A. Botha, D. Van Greunen and M. Herselman. "Mobile human-computer interaction perspective on mobile learning". In Proceedings of the 6th annual international conference on computing and ICT research (Kampala, Uganda, 2010), pp. 3-18. 2010.

[3] S. Jumisko-Pyykkö and T. Vainio. "Framing the context of use for mobile HCI". International journal of mobile human computer interaction (IJMHCI), vol. 2, no. 4, pp. 1-28, 2010.

[4] Y. J. Moogan. "Can a higher education institution's marketing strategy improve the student-institution match?" International journal of educational management, vol. 25, no. 6, pp. 570-589, 2011. DOI http: //dx.doi.org/10.1108/09513541111159068

[5] P. A. Harpur and M. R. De Villiers. "Can mobile technology reduce the Digital Divide? A study in a South African tertiary education context". In J. Steyn and M. Kirlidog (editors), Proceedings of the 6th International Development Informatics Association (IDIA) conference. Istanbul, Turkey. 2012.

[6] C. K. Coursaris and D. J. Kim. "A meta-analytical review of empirical mobile usability studies". Journal of usability studies, vol. 6, no. 3, pp. 117-171, 2011.

[7] R. Deegan and P. Rothwell. "A classification of mlearning applications from a usability perspective". Journal of the Research Center for Educational Technology, vol. 6, no. 1, pp. 16-27, 2010. 
[8] L. F. Motiwalla. "Mobile learning: A framework and evaluation". Computers \& education, vol. 49, no. 3, pp. 581-596, 2007. DOI http://dx.doi.org/10.1016/j compedu.2005.10.011

[9] A. Botha, K. Calteaux, M. Herselman, A. S. Grover and E. Barnard. "Mobile user experience for voice services: A theoretical framework". In Proceedings of M4D 2012 (28-29 February 2012 New Delhi, India), p. 335. 2012.

[10] M. Tedre, M. Apiola and J. C. Cronjé. "Towards a systemic view of educational technology in developing regions". In AFRICON 2011, pp. 18. IEEE, 2011. DOI http://dx.doi.org/10.1109/ afrcon.2011.6072012

[11] G. N. Vavoula and M. Sharples. Meeting the challenges in evaluating mobile learning: A 3-level evaluation framework. IGI Global, 2009.

[12] S. Ssemugabi and M. R. De Villiers. "Effectiveness of heuristic evaluation in usability evaluation of elearning applications in higher education". South African computer journal, vol. 45, pp. 26-39, 2010.

[13] A. Dix, J. Finlay, G. Abowd and R. Beale. Humancomputer interaction. Pearson Education, 2004.

[14] J. Preece, H. Sharp and Y. Rogers. Interaction designBeyond human-computer interaction. John Wiley \& Sons, 2015.

[15] J. Kjeldskov and J. Paay. "A longitudinal review of mobile HCI research methods". In Proceedings of the 14th international conference on human-computer interaction with mobile devices and services, pp. 6978. ACM, 2012. DOI http://dx.doi.org/10.1145/ 2371574.2371586

[16] R. Heeks. The ICT4D 2.0 manifesto: Where next for ICTs and international development? University of Manchester. Institute for development policy and management (IDPM). Development informatics group, 2009. URL http://www.sed.manchester.ac.uk/ idpm/research/publications/wp/di/index.htm

[17] P. M. Napoli and J. A. Obar. "Mobile leapfrogging and digital divide policy: Assessing the limitations of mobile Internet access". Fordham University Schools of Business research paper, 2013.

[18] A. Botha, I. Makitla, M. Ford, T. Fogwill, D. Seetharam, C. Abouchabki, J. Tolmay and O. Oguneye. The mobile phone in Africa: Providing services to the masses. CSIR, 2010.

[19] Student Brands. "Higher education institutions introduce technology enhanced learning", 2014. URL http://www.studentbrands.co.za/highereducation-institutions-introduce-technologyenhanced-learning/

[20] J. Traxler. "Defining mobile learning". In IADIS international conference on mobile learning, pp. 261266. 2005.

[21] A. Mostakhdemin-Hosseini and J. Tuimala. "Mobile learning framework". In IADIS international conference on mobile learning, pp. 203-207. 2005.

[22] M. Sharples, J. Taylor and G. Vavoula. "A theory of learning for the mobile age". In R. Andrews and C. Haythornthwaite (editors), The SAGE handbook of e-learning research, pp. 221-247. Sage Publications, 2007.
[23] T. Georgiev, E. Georgieva and A. Smrikarov. "Mlearning-A new stage of e-learning". In International conference on computer systems and technologies (CompSysTech), pp. 1-4. 2004.

[24] International Organization for Standardization (ISO). "ISO 9241-11: Ergonomic requirements for office work with visual display terminals (VDTs) - Part 11: guidance on usability", 1998.

[25] Y. G. Ji, J. H. Park, C. Lee and M. H. Yun. "A usability checklist for the usability evaluation of mobile phone user interface". International journal of human-computer interaction, vol. 20, no. 3, pp. 207-231, 2006. DOI http://dx.doi.org/10.1207/ s15327590ijhc2003_3

[26] International Organization for Standardization (ISO). "ISO 9241-210: Ergonomics of human system interaction-Part 210: human-centred design for interactive systems", 2009.

[27] D. A. Norman. The invisible computer: Why good products can fail, the personal computer is so complex, and information appliances are the solution. MIT press, 1998.

[28] E. L.-C. Law, V. Roto, M. Hassenzahl, A. P. Vermeeren and J. Kort. "Understanding, scoping and defining user experience: A survey approach". In Proceedings of the SIGCHI conference on human factors in computing systems, pp. 719-728. ACM, 2009. DOI http://dx.doi.org/10.1145/1518701. 1518813

[29] N. Bevan. "What is the difference between the purpose of usability and user experience evaluation methods". In Proceedings of the workshop UXEM, vol. 9. 2009.

[30] J. McCarthy and P. Wright. "Putting 'felt-life' at the centre of human-computer interaction (HCI)". Cognition, technology \&6 work, vol. 7, no. 4, pp. 262-271, 2005. DOI http://dx.doi.org/10.1007/ s10111-005-0011-y

[31] A. Botha, M. Herselman and D. van Greunen. "Mobile user experience in a mlearning environment". In Proceedings of the 2010 annual research conference of the South African Institute of Computer Scientists and Information Technologists (SAICSIT), pp. 2938. ACM, 2010. DOI http://dx.doi.org/10.1145/ 1899503.1899507

[32] S. S. Masemola and M. R. De Villiers. "Towards a framework for usability testing of interactive e-learning applications in cognitive domains, illustrated by a case study". In D. Bishop, J. \& Kourie (editor), Proceedings of the annual research conference of the South African Institute of Computer Scientists and Information Technologists (SAICSIT), pp. 186-197. 2006.

[33] H. Petrie and N. Bevan. "The evaluation of accessibility, usability and user experience". In The universal access handbook, pp. 10-20. CRC Press, 2009.

[34] V. Roto, M. Obrist and K. Väänänen-Vainio-Mattila. "User experience evaluation methods in academic and industrial contexts". In Interact 2009 conference: User experience evaluation methods in product development (UXEM'09), Uppsala, Sweden. Citeseer, 2009.

[35] W. Albert and T. Tullis. Measuring the user experience: Collecting, analyzing, and presenting usability metrics. Newnes, 2013. 
[36] S. Leshem and V. Trafford. "Overlooking the conceptual framework". Innovations in education and teaching international, vol. 44, no. 1, pp. 93-105, 2007. DOI http://dx.doi.org/10.1080/ 14703290601081407

[37] M. B. Miles and A. M. Huberman. Qualitative data analysis: An expanded sourcebook. Sage, 1994.

[38] A. Macintosh and A. Whyte. "Towards an evaluation framework for e-participation". Transforming government: People, process and policy, vol. 2, no. 1, pp. 16-30, 2008.

[39] M. M. Yusof, J. Kuljis, A. Papazafeiropoulou and L. K. Stergioulas. "An evaluation framework for health information systems: Human, organization and technology-fit factors (HOT-fit)". International journal of medical informatics, vol. 77, no. 6, pp. 386-398, 2008. DOI http://dx.doi.org/10.1016/ j.ijmedinf.2007.08.011

[40] M. R. De Villiers and P. A. Harpur. "Design-based research - the educational technology variant of design research: Illustrated by the design of an m-learning environment." In P. Machanick and M. Tsietsi (editors), Proceedings of the South African Institute for Computer Scientists and Information Technologists conference, pp. 252-261. 2013.

[41] H. A. Simon. The sciences of the artificial, vol. 136. MIT press, 1996.

[42] A. R. Hevner, S. T. March, J. Park and S. Ram. "Design science in information systems research". Management information systems quarterly, vol. 28, no. 1 , pp. 75-105, 2004.

[43] S. T. March and V. C. Storey. "Design science in the information systems discipline: An introduction to the special issue on design science research". Management information systems quarterly, vol. 32 , no. 4, p. 6 , 2008.

[44] K. Peffers, T. Tuunanen, M. A. Rothenberger and S. Chatterjee. "A design science research methodology for information systems research". Journal of management information systems, vol. 24, no. 3 , pp. 45-77, 2007. DOI http://dx.doi.org/10.2753/ MIS07421222240302

[45] T. Amiel and T. C. Reeves. "Design-based research and educational technology: Rethinking technology and the research agenda". Journal of educational technology \&s society, vol. 11, no. 4, pp. 29-40, 2008.

[46] S. Barab and K. Squire. "Design-based research: Putting a stake in the ground". The journal of the learning sciences, vol. 13, no. 1, pp. 1-14, 2004. DOI http://dx.doi.org/10.1207/ s15327809jls1301_1

[47] F. Wang and M. J. Hannafin. "Design-based research and technology-enhanced learning environments". Educational technology research and development, vol. 53, no. 4, pp. 5-23, 2005. DOI http://dx.doi.org/10. 1007/BF02504682

[48] H. Teräs and J. Herrington. "Neither the frying pan nor the fire: In search of a balanced authentic elearning design through an educational design research process". The international review of research in open and distributed learning, vol. 15, no. 2, 2014.

[49] K. Väänänen-Vainio-Mattila, V. Roto and M. Hassenzahl. "Towards practical user experience evaluation methods". In E.-C. Law, N. Bevan, G. Christou, M. Springett and M. Lárusdóttir (editors), Meaningful measures: Valid useful user experience measurement (VUUM), pp. 19-22. 2008. URL http://research.nokia.com/files/ VaananenVainioMattila-VUUM.pdf.

[50] J. Nielsen. "Ten usability heuristics", 2005. URL Www.useit.com/papers/heuristic/heuristic_list. html Last checked: June 2011.

[51] D. Squires and J. Preece. "Predicting quality in educational software: Evaluating for learning, usability and the synergy between them". Interacting with computers, vol. 11, no. 5, pp. 467-483, 1999. DOI http: //dx.doi.org/10.1016/S0953-5438(98)00063-0.

[52] A. Herrington, J. Herrington and J. Mantei. "Design principles for mobile learning". In I. O. J. Herrington, A. Herrington and B. Ferry (editors), New technologies, new pedagogies: Mobile learning in higher education, pp. 129-138. University of Wollongong, 2009.

[53] A. Karoulis and A. Pombortsis. "Heuristic evaluation of web-based ODL programs". In C. Ghaoui (editor), Usability evaluation of online learning programs, pp. 88-109. Idea Group Inc, UK, 2003. DOI http://dx doi.org/10.4018/978-1-59140-105-6.ch005

[54] M. Sharples. "Learning as conversation: Transforming education in the mobile age", 2009. URL http://www fil.hu/mobil/2005/Sharples_final.pdf

[55] J. Nielsen. "Mobile usability update", 2011. URL http://www.useit.com/alertboc/mobileusability.html. Last checked: June 2011.

[56] O. Savolainen. User experience design in open source development: Approaches to usability work in the Moodle community. Master's thesis, University of Tampere, 2010 .

[57] M. Sharples, J. Taylor and G. Vavoula. "Towards a theory of mobile learning". In Proceedings of mLearn 2005, pp. 1-9. 2005.

[58] T. Cochrane. "Learning with wireless mobile devices and social software". In Who's learning? Whose technology? Proceedings of ascilite (Sydney 2006). Citeseer, 2006.

[59] S. B. Zaibon and N. Shiratuddin. "Heuristics evaluation strategy for mobile game-based learning". In 6th IEEE international conference on wireless, mobile and ubiquitous technologies in education (WMUTE), 2010, pp. 127-131. IEEE, 2010. DOI http://dx.doi.org/ 10.1109/wmute.2010.27

[60] M. N. Beccari and T. L. Oliveira. "A philosophical approach about user experience methodology". In Design, user experience, and usability: Theory, methods, tools and practice, pp. 13-22. Springer, 2011. DOI http://dx.doi.org/10.1007/ 978-3-642-21675-6_2

[61] A. Jones, K. Issroff, E. Scanlon, G. Clough, P. McAndrew and C. Blake. "Using mobile devices for learning in informal settings: Is it motivating?" In IADIS international conference on mobile learning. IADIS Press, 2006.

[62] M. Sharples, I. Arnedillo-Sánchez, M. Milrad and G. Vavoula. "Mobile learning: Small devices, big issues". In N. B. et al. (editor), Technology-enhanced learning: Principles and products, pp. 233-249. Dordrecht, Netherlands: Springer, 2009. DOI http: //dx.doi.org/10.1007/978-1-4020-9827-7_14 
[63] S. R. Trollip and S. M. Alessi. "Multimedia for learning: Methods and development", 2001.

[64] M.-A. Storey, B. Phillips, M. Maczewski and M. Wang. "Evaluating the usability of Web-based learning tools". Journal of educational technology $\&$ society, vol. 5, no. 3, pp. 91-100, 2002.

[65] C. Smith and J. Cook. "Interaction heuristics for context-sensitive mobile learning". In Proceedings of the 3rd Work-based Learning for Educational professionals (WLE) mobile learning symposium: Mobile learning cultures across education, work and leisure (London, 2009), pp. 1-3. 2009.

[66] A. Göker and H. Myrhaug. "Evaluation of a mobile information system in context". Information processing 83 management, vol. 44, no. 1, pp. 3965, 2008. DOI http://dx.doi.org/10.1016/j.ipm. 2007.03 .011

[67] J. Traxler. "The 'learner experience' of mobiles, mobility and connectedness". In ELESIG symposium: Digital futures, vol. 21. 2010.

[68] P. Kroeker and M. Ally. "Interaction strategies for mobile learning". In IADIS international conference on mobile learning. 2005.

[69] M. Pirker and R. Bernhaupt. "Providing feedback to UX designers using UX evaluation methods". In Proceedings of CHI 2011, Vancouver, BC, Canada, pp. 7-12. 2011.

[70] M. Hassenzahl. "User experience (UX): Towards an experiential perspective on product quality". In Proceedings of the 20th international conference of the Association Francophone d'Interaction Homme-Machine, pp. 11-15. ACM, 2008. DOI http://dx.doi.org/10. 1145/1512714.1512717.

[71] J. Roschelle. "Unlocking the learning value of wireless mobile devices". Journal of computer assisted learning, vol. 19, no. 3, pp. 260-272, 2003. DOI http://dx.doi. org $/ 10.1046 / j .0266-4909.2003 .00028 . x$ 


\section{APPENDIX A: FINAL MUUX-E FRAMEWORK}

\section{Category 1: General Interface Usability [27 Sub-criteria]}

1. Visibility of system status

1.1. Feedback is provided by the application.

1.2. The system is responsive to user actions without odd and unexplained events.

1.3. Visible feedback icons communicate what is happening.

2. Match to the real world

2.1. Clear everyday understandable language has been used in the application.

2.2. Where metaphors are used they represent real-world objects, ideas and concepts.

2.3. Symbols and icons follow an intuitive pattern in line with tasks.

2.4. Information is seen as sequential, logical and as naturally arranged.

3. Learner control and freedom

3.1. Users are able to exert control on the system.

3.2. It is possible to exit at any time even though mistakes might have been made.

3.3. Undo and Redo options exist.

4. Consistency; adherence to standards

4.1. Patterns of words, symbols, icons repeat logically throughout the application.

4.2. Platform standards are recognised as similar to PC-oriented standards.

5. Prevention of usability-related errors

5.1. Errors are preventable - the system is designed to take care of this.

5.2. An appropriate message is shown if a mistake is made.

6. Recognition rather than recall

6.1. Objects are visible and familiar; scrolling is needed occasionally.

6.2. The screen is manipulated to view any information without needing to remember.

6.3. Advice on system use is visible and able to be used whenever needed.

6.4. Simple displays are presented with few or no multiple page display options.

6.5. The zoom feature enables easy enlargement of text for improved reading.

7. Aesthetics and minimalism in design

7.1. Distracting material of minimal relevance has been excluded.

7.2. Graphics are used to illustrate a point rather than to decorate the page.

8. Recognition and recovery from errors

8.1. Error messages are easy to follow being presented in straight forward language.

8.2. Quick and simple solutions are offered if errors are made.

8.3. Recovery is achieved after constructive help.

9. Help and documentation

9.1. A help facility exists, it is easy to find and support the users' needs.

9.2. A search facility makes it easy to find information.

9.3. Support documentation is provided on each page.

\section{Category 2: Web-based learning [19 Sub-criteria]}

10. Simple, well-organised navigational structure

10.1. The application is easy to navigate on a mobile handheld device.

10.2. There are several paths to and from a chosen destination.

10.3. Related information has been grouped into obvious categories.

10.4. Information is organised hierarchically.

10.5. Links and buttons support navigation throughout the site without cluttering it.

11. Relevant pedagogical site content

11.1. The site is interesting and keeps the user's attention focused.

11.2. Site information is clear and relevant.

11.3. No racial or gender biases are noted.

11.4. If material has been copyrighted, this has been made clear.

12. Information easily accessible

12.1. Any lesson material or downloadable documents can be reached.

12.2. The videos open with ease. 
12.3. All links to external sites provide the required connections to additional information.

13. Suitable course content of a high quality

13.1. Additional website links provide suitable content.

13.2. The content is of a high standard.

14. Easy-to-use system, called easiness

14.1. No difficulties are experienced reaching site material via the mobile interface.

14.2. It is just as easy to scroll or browse back to the site after visiting another site.

14.3. It is easy to browse back and forth through the many learning options offered.

15. Excellent video and digital media

15.1. Text is presented in a legible easy to read format.

15.2. Digital material is of a high quality, no difficulty is experienced during viewing.

Category 3: Educational usability [11 Sub-criteria]

16. Clarity of goals, objectives and outcomes

16.1. Goals are clearly set out, objectives and expected outcomes for learning are clear too.

16.2. There is a good reason for the inclusion of each page and this reason is obvious.

17. Effectiveness of collaborative learning

17.1. Activities are experienced encouraging collaborative learning in several different ways.

17.2. The discussion forum is fun and operational.

17.3. Chat room facilities are found.

18. Error recognition, diagnosis and recovery

18.1. Problem-based learning strategies have been implemented.

18.2. Mistakes can be made affording users the chance to learn from them.

18.3. Help is provided to recover from cognitive errors.

19. Feedback, guidance and assessment

19.1. Users receive prompt feedback from the application on assessment and progress.

19.2. Guidance is provided about the tasks and construction of knowledge going on.

19.3. Activities are graded with grades providing instant feedback and correction.

Category 4: m-Learning features [39 Sub-criteria]

20. Handheld devices and technology

20.1. Technology has made mobile learning feasible.

20.2. The mobile handheld device has adequate capabilities to support mobile learning.

20.3. The mobile interface does not hamper working with the application.

20.4. Inserting text and numbers is feasible and achievable.

20.5. The mobile handheld device system is used to its fullest capability.

20.6. Mobile communication channels are provided.

21. Contextual factors (pragmatic)

21.1. A physical environment is noted but it does not hinder the lesson experience.

21.2. The lessons in followed where noise and audible interference is experienced.

21.3. Prior mobile handheld device knowledge and exposure makes the task easy.

21.4. User characteristics have been considered as part of the exercise.

21.5. Goals are set and not adjustable.

21.6. The application feels and behaves like a normal working environment.

21.7. During the lesson, awareness of surroundings is evident.

21.8. Users are exposed to rich and complex environments, not limited by the mobile.

22. User-centricity (pragmatic)

22.1. Support for personal approaches to learning is offered.

22.2. Experimentation and exploration is possible.

22.3. User requirements have been specified.

22.4. Self-sufficiency is observed.

22.5. Material is presented in a clear, student-centred format.

22.6. Focus is enhanced in that students spend longer times doing tasks.

22.7. Personalised learning format has been provided.

22.8. Students are personally aware of all content with control being given to users. 
22.9. Students can customise, applying their own preferences.

22.10. Active learning promotes critical thinking: users compare, analyse, classify, deduce.

22.11. Users are able to direct their own learning with a sense of ownership.

\section{Flexibility}

23.1. The lesson may be done at any personal moment in time.

23.2. An adaptable environment has been created.

23.3. Lesson information may be viewed in any order.

23.4. The system can be adjusted to individual needs.

23.5. The systems can be used anytime and anywhere.

24. Interactivity

24.1. Navigational fidelity is experienced.

24.2. Multimedia components are appropriate.

24.3. Multiple kinds of exercises have been provided.

24.4. Synchronous communication is possible.

24.5. Asynchronous communication is possible.

24.6. Interaction happens in varying ways.

24.7. Interaction with the application is smooth.

24.8. Support is provided for interactivity with the application.

24.9. Interactivity has been encouraged in creative ways.

\section{Category 5: User experience [21 sub-criteria]}

\section{Emotional issues}

25.1. The lessons are motivating and fun.

25.2. The application encourages participation with a longer time trying to process the lesson.

25.3. The experience is enjoyable.

25.4. It is new technology yet it is interesting and an acceptable form of learning.

25.5. This way of learning software engineering is exciting.

26. Contextual factors (hedonic)

26.1. Knowledge of mobile technology makes this way of learning a pleasure.

26.2. The need for this type of learning suits the current mobile learner environment.

27. User-centricity (hedonic)

27.1. Personalised learning is encouraged.

27.2. The student is able to customise the learning environment.

28. Social value

28.1. The application is social, encouraging media sharing

28.2. The m-learning approach provides both synchronous and asynchronous interaction.

29. Needs

29.1. The student is encouraged to express personal opinions.

29.2. The learning environment is stimulating.

29.3. A sense of security is achieved.

30. Appeal

30.1. New impressions of the learning content create an appealing space.

30.2. The student is motivated to explore.

30.3. The experience is visually appealing.

31. Satisfaction

31.1. The experience adds fun to the learning opportunity.

31.2. This way of learning is motivating.

31.3. A satisfying sense of achievement is felt.

31.4. The student is encouraged to engage with the course material. 


\section{APPENDIX B: AN EXTRACT FROM THE HEURISTIC EVALUATION SURVEY-EXPERTS}

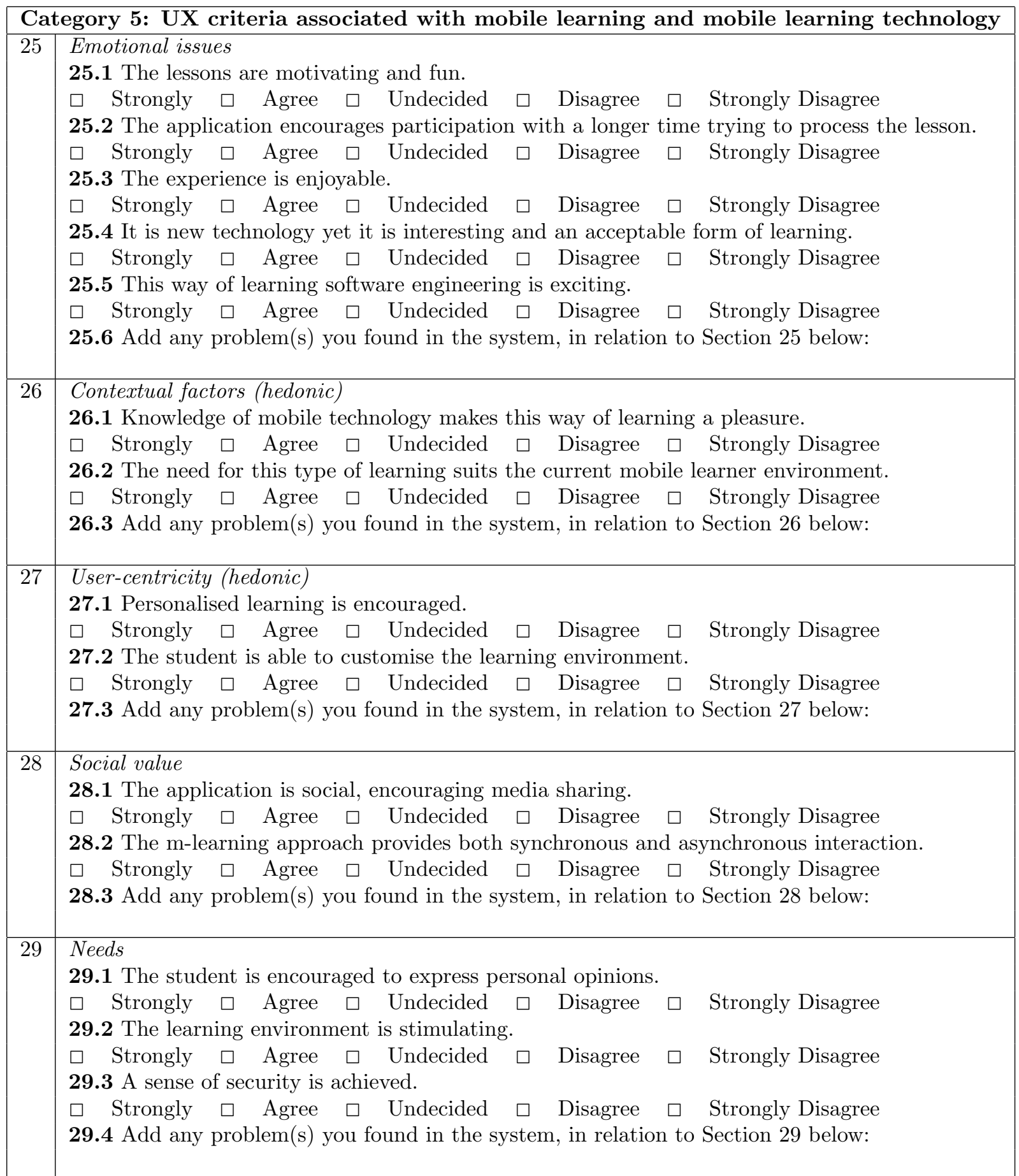

